\title{
Raising Process-Genre Awareness: A Proposal of ESP Writing Lesson Plan
}

\author{
Bingqian Du \\ The Training Center of Ministry of Education for Studying Overseas, Northeast Normal University, Changchun \\ China \\ Email: dubq526@nenu.edu.cn
}

Received 5 March 2015; accepted 14 April 2015; published 21 April 2015

Copyright (C) 2015 by author and Scientific Research Publishing Inc.

This work is licensed under the Creative Commons Attribution International License (CC BY). http://creativecommons.org/licenses/by/4.0/

(c) (i) Open Access

\begin{abstract}
Studies on EFL writing in the literature have shed light on process or genre approach of teaching writing to college or secondary EFL learners (Bhatia, 1999; Cheng, 2006; Chen \& Su, 2012; Guo, 2005; Hyland, 2003, 2007; Swales, 1990). To date, scarce related works have centered on improving the EFL writing of the Chinese visiting scholars, who have a strong motivation to publish articles in English. These scholars generally attend an ESP training program before living and conducting research in English-medium countries for one year. This proposed lesson plan is designed as a sample session of one core course, ESP Writing, of the training program, this proposed lesson plan is designed as one component of such training program, synthesizing the process approach and genre approach of teaching writing to a group of non-English majored Chinese visiting scholars. It is primarily aimed to raise these college teachers' awareness of the significance of purposes, author-reader relationship, expectations, genre features and functions, cultural differences, and the impacts of how the author chooses to consider these factors. This sample lesson plan seeks to exemplify a synthesis of process-genre approach instead of traditional writing instruction in this writing course. This specific EFL writing lesson plan thus describes tasks and activities in great detail following a process-genre approach of teaching and learning. The scholars are assigned to write a request email in stages such as prewriting, co-construction, peer review, and proofreading. It employs innovative teaching methods to help students write purposely, appropriately, and effectively. Various recourses are used as input such as online authentic data and native speakers' testimonies to create an authentic specific context for students to recognize the significance of purposeful writing. Specific procedures are suggested for instructors to incorporate process-genre approach into their teaching experience.
\end{abstract}

\section{Keywords}

Process-Genre Approach, Purposes, Awareness, EFL Writing 


\section{Introduction: Theoretical Background}

The process approach of teaching writing regards wring as a "process" rather than a "product". Writing should not be a "once-for-all" activity; rather, the process of writing is emphasized. Grammar and accuracy are only one part of the criteria for a good piece of writing. A genre approach of writing takes into consideration of the context, the reader, and the interpretation of the writer's intended meaning (purposes). These enrich the take-in of the writing product to be an individualized and variable recursive process with much attention directed at genre effects. So teaching writing means teaching students to "discover" by themselves and form their own "voice". Students would make their own decisions (a mental activity) to include what to write and how to convey their "voice" (process approach, cf. Zamel, 1983). Writing is also an activity of social interaction. In order to meet the contextual purposes, writing should conform to the styles of particular genres (genre approach) (Hyland, 2007). To a large extent the purposes play an important role in writing in a social context. Therefore, it is plausible to synthesize a process approach with a genre approach of viewing writing.

All of the above are perceptions when we, as teachers, adopt approaches to teach writing. As Kuzborska (2012) states, "teachers" beliefs influence their goals, procedures, materials, classroom interaction patterns, their roles, their students, and the school they work in (p. 102). The lesson plan this paper presents has responded to these issues by showing what impacts these aspects (purposes, genres, social contexts, language styles, personal factors) have on the writing class. This lesson plan adopts a process-genre approach in teaching writing, focusing on raising meta-cognitive awareness of students to consider many factors (such as genres, purposes, language styles) that may influence the effectiveness of their writings following procedures such as prewriting, drafting, peer reviewing, revising, proofreading, and other steps that manifest the process approach.

The underpinning theories involved in designing this sample lesson plan are in accordance with the overreaching goals of the writing course. The target students are Chinese visiting scholars who want to know how to survive in English-speaking countries (survival English). Academic English is also necessary for them to communicate with host universities, professors and communicate at international conferences. This teaching plan aims to lead students to discover characteristics of good writing by comparisons between and discussions about successful request emails and less well-written ones, and differences between letter written by a Chinese author and by a native writer (discovering the context); Their recognition of purposes and the deliberate focus on genres help them to write accordingly (through the entire composing procedure); The access to authentic writing environment and real-life situations are also enacted; Language scaffolding which gives them more choices concerning the genre style of a request email is also provided. All of these are aimed at raising their process-genre awareness, which seems to be one of the biggest obstacles for Chinese L2 learners.

In this sample lesson plan, students are motivated to write more effectively by breaking down the writing process into manageable pieces; They are required to reflect on their own writing and revise them (for example, the peer review); Comments are given as objectively as possible (which could be done in the joint construction step where their own advice can be voiced). These steps reflect the deliberation of raising their awareness of the process of writing.

By synthesizing the process approach and genre approach, the specific goals of this writing lesson can be summarized as follows: Student teachers will know how to adhere to a specific purpose and genre, pay sufficient attention to writing procedures and adapt their writing time by time, notice how changing the language results in variation of functions; they will also be given opportunities to peer-review and learn to assess and qualify a piece of writing. The process approach has the greatest possibility to foster their conception of viewing writing as can be revised, valuing peer scaffolding as a resourceful input, and discovering (by themselves) what aspects need special attention to achieve the goal of persuasion. The genre approach serves best when students consider purposes, language styles, and the communicative effectiveness of their writing in the social context (which is about the need to convince addressee that the grant of leave is reasonable and necessary).

\section{The Setting}

Several social variables are discussed before the sample lesson plan is introduced in the next section:

Social context. China is now sending many outstanding university teachers going abroad every year, who need to improve their English proficiency before they are approved by the Government to go to English-speaking countries. The China Scholarship Council requires a high-quality training of them; it administers a national English proficiency test for them. Thus the English teaching in such context differs a lot from teaching 
undergraduate and graduate students.

The exam. The national exam comprises 2 writing tasks: a piece of daily life writing based on daily life situations and an academic argumentative writing based on social issues. For example, they are required to write complaint letters about a machine ( $1^{\text {st }}$ writing), and to write to give their opinions about a current social issue such as the prohibition of offering plastic bags in shopping malls ( $2^{\text {nd }}$ writing).

\section{The Lesson Plan}

(a) The Time Frame: a 90-minute course (without break) at the end of the first month of a semester.

(b) Specific purpose of this writing class: students will learn how to make a successful request for a leave from the host institution they visit through emails.

Specific objectives of this writing class:

1. Students will recognize why there is a need to connect the purpose of the writing to the genre of an email request.

2. Students will notice the importance of providing and explaining the acceptable reason in a request email (including the exact time for a leave, pointing to a specific place where the conference will be held, etc.).

3. Students will recognize the need to raise the awareness that different language use will convey different tones, feelings and functions and thus influencing the communicative effectiveness and the purpose of the writing.

4. Students will understand the structure of a request email.

5. Students will be able to revise and evaluate a request email.

(c) The target students. The students in this lesson plan are Chinese visiting scholars who are going abroad and thus need to pass a national English exam held by the Chinese Scholarship Council. In other words, they are adults, and they are non-English major college teachers, whose academic concerns are mostly in the fields of hard science. In addition, they are around their $30 \mathrm{~s}$ to $50 \mathrm{~s}$. After their Ph.D. graduation, they seldom receive any formal instruction on any area of English learning. But they are good at reading English academic research articles and scientific reports, demonstrating that most of them are at the intermediate and advanced levels of the English language proficiency. They are experienced teachers and excellent scholars in their own academic circles. Their confidence in themselves sometimes might pose a hardship for the instructors of this program to convince them of writing in a novel way instead of following their old traditional style. Since on average they received their formal training of English at least a decade ago, they may have less awareness of the relationship between writing, discourse and social aspects.

Students' research fields: Finance; engineering; mathematics; environmental sciences; automobile mechanics; neurology; architecture, etc.

Students' academic qualifications: professors, associate professors, and lecturers.

Students' degrees: All of them have received a doctor's degree.

Students' age: 28 - 35 (10 students/class); 35 - 45 (20 students/class); 45 - 55 (10 students/class).

Students' previous writing training: Few of them have received formal training of writing. Only English language as a general subject was taught fromthe time they graduated from secondary schools until they started to work.

They have only partial knowledge of the process-genre approach of writing; therefore, there is a need to raise their awareness of genres, purposes, the drafting stages, and critical thinking during writing. Their writing techniques are traditional, and largely translative.

(d) Activities, Rationales, Procedures and Materials:

Step 1: Discovering the goal and the features (30 minutes).

Drawing on the genre approach, in this "developing context" prewriting step students learn to recognize the significance of analyzing the purpose, the addressee, the cultural difference (oriental vs. western), and how the achievability would depend on them in a request email. To explain the situation, the teacher first asks them to summarize how they write request emails before. Then he presents handouts of emails and ask how well these emails are written, how the writers achieved that purpose, and what features those emails have. The summary of those features is a genre-approach attempting to draw students' attention to the specific genre features of "request email". As the students are researchers themselves, they would like to know the reasons and specific procedures of carrying out writing in this novel approach.To give rationale of the significance of the relationship 
between genres and purposes, a quotation from Hyland can be shown in the PPT slide: "Themes are best seen as real-life activities in which people do specific things through writing, providing potentially relevant and motivating ways into writing by drawing on students' personal experiences and prior knowledge” (Feez, 1998, cited in Hyland, 2007: p. 154).

In this way, students can read through the materials with a specific goal and discover by themselves about the language features, the social norms, etc. The materials here are genuine request emails and samples adpapted from the internet (with a little revision on some grammatical mistakes), serving as stimuli and exploratory materials for students. The following email samples will take up 3 minutes for them to have a glance at. (It can be the case that for adult learners like these visiting scholars and college teachers, the amount of time teachers give to a certain task is. The allocation of time depends on the different emphases the teacher intends to put on different task. So the teacher may choose to add 2 more minutes in this step.)

Follow-up questions then can be asked, such as "what is usually the first sentence they say in the request emails", in the hope that students will recognize how important purpose analysis is.

After students have noticed the need to give sufficient attention to purposes, another question is posed to them: "Which do you think is written by a Chinese writer? If you were the addressee, which of the following would fail to achieve that purpose? Why do you think it would fail?”

These questions lead the students to think about the purpose deeper. The achievability of the goal is constrained by so many variables that writing a seemingly simple request email is not that simplistic. This will also motivate students to plan more thoroughly in the first step of drafting and pre-planning (the process-approach).

To raise their awareness of the importance of genres, 2 emails out of the 5 they have just read are highlighted for students to find out which one is the more effective and why. They are allowed to discuss with their peers about these two emails after reading a checklist (teachers should point out that it is not necessary to follow every step in the checklists and these checklists might invoke adaptations depending on different situations. The teacher cal also prompt students to envision what other factors would result a different choice). Throughout their discussion, the teachers walk around the classroom to scaffold students' discussion. The whole design of this discussion activity is based on Vygosky's (1987) social constructivist approach that the MKO could be the teacher and more proficient peers. Besides, this session combines extensive reading with students' critical thinking. These checklists are only provided as one POSSIBLE reference, not standard criteria or an authority. Students are encouraged to discover by themselves what guidelines could be useful to their own context and what NOT (when they are writing these request emails for a leave to their host professors after they go abroad). This also enhances their sense of involvement and engagement in classroom discourse. Students may feel they have the autonomy to revise if necessary. This also caters to their identity as scholars and successful college teachers who might have a high research efficacy.

The teacher can ask students to point out what exactly makes the successful one successful, and less wellwritten one less successful based on the real situation (i.e. the purpose of a request email of asking for a leave to attend an international conference). Everyone then may receive a table (on a piece of paper) to list their answers. After they have worked out which is the better one and figured out why in the table, the teacher will construct the understanding of this genre together with students (by checking which guidelines the whole class agree to be used in their writing). Teacher-students joint knowledge construction addresses the learning and researching habits of the learners since the teacher-researchers are always looking for the ultimate and absolutely truth and are less tolerant for ambiguity and vagueness. For them, what is true and what is false are equally important. The teacher needs to avoid providing anything unanswered. For this reason, a native expert's comment on these two highlighted email samples is given as additional criterion (Had better a video, depending on the time limit). This expert's reference will testify students' hypothesis about qualities of a good request email. In the end, students need to be warned that "genre" doesn't equal to "template". There are lots of templates on the internet which should not be imported directly.

The teacher then should draw students' attention to the role the writer plays as opposed to the addressee. That is, in order to get the desirable result, what specifically is the stance for the writer to take? What tone will the email be set in? Is it an order or a command? What is the suitable structure of the requesting sentence? To answer the above questions, students are asked, based on their own experience, how they expect their students to write if they were the addressee. By imagining creating the authentic situation involving students themselves, students can learn that the writer's role is closely related to the purpose: persuading the addressee that there is a justifiable reason for the writer to put the conference as a priority to the addressee's class on that day. So the 
sub-goal is that the writer succeeds convincing the host professor to agree with him that the leave needs to be approved. This will remind the students of the crucial part in writing this request email: how will the writer convince the addressee to sympathize with the writer and agree on the reason for his missing the class?

According to the Bulge Theory (Wolfson, 1988), if the social relationship between the writer and the professor is too distant, there will be expressions of a high degree of politeness. However, if their relationship has been casual and more like a friendship, politeness will not be the writer's major concern. If the students all agree that they should write formally with a high degree of politeness, they are asked to suggest several polite expressions.

Step 2: Language (vocabulary and sentence structure) scaffolding (20 minutes).

This is a step of deconstructing the text in a genre approach of teaching writing. By recalling the previous activities, students' attention is drawn to the different writer stances (requesting, causing others trouble) and the addressee (accepting or rejecting others' requests). The purpose is to let them notice that these all influence the language they are going to write in. Then the teacher will ask them: How can you describe your feelings when you recognize that you will cause someone trouble? Do you describe your feelings in a request letter? An online vocabulary learning activity can make it even more interesting ${ }^{1}$ :

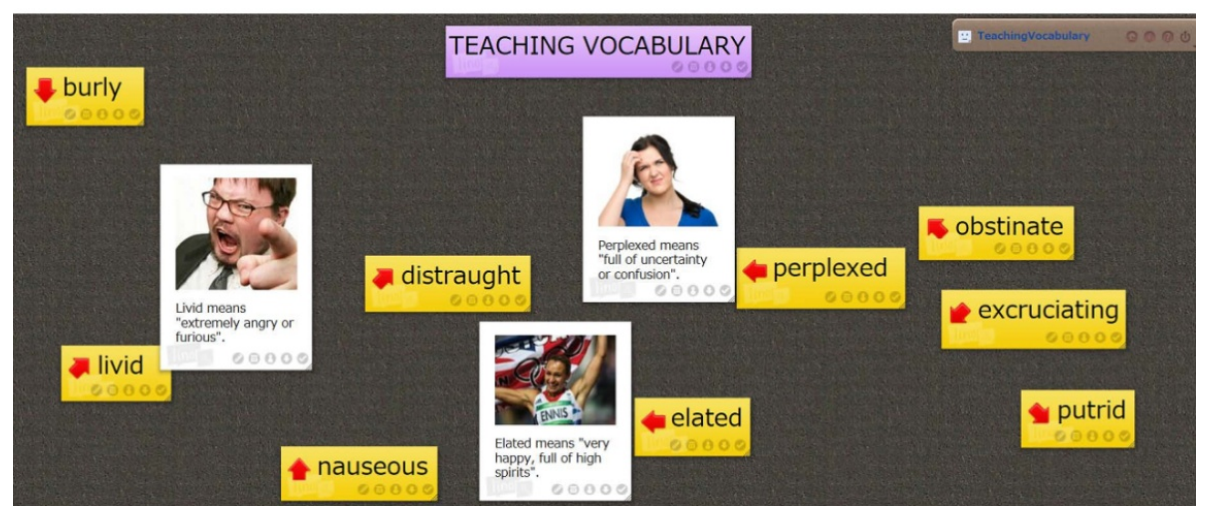

Students will learn that "I have some personal stuff to do" is more vague than "I need to take my sick grandmother to hospital at Friday afternoon every week at 2:30 p.m.”, which is more persuasive.

Further questions can be asked: Should they state the motive (asking for a leave) at the very beginning of an email? Should they express their sorry in the end? How many paragraphs should there be? What are necessary parts of any email? What are important verbs? Adjectives?

After this activity, students should know: first of all, to make a request like a request, the writer needs to point out the exact time he is asking for a leave, the exact date when he intends to miss the tutorial, or the exact emergency that forces him to ask for a leave. Secondly, students need to understand what makes an excuse excusable. The writer should state the excuse clearly, which in this case means convincing the addressee of the authenticity of the international conference. This could be achieved by providing exact and detailed information, i.e. the location, the time, the conference name, the significance of the conference. The writer can also increase the seriousness of the excuse as truthfully as possible by avoiding using too many hedging words or vague expressions such as "something" or "personal reason".

Step 3: modeling (5 minutes).

This step draws on the second stage of a genre approach of teaching writing. Teachers can briefly summarize what have been discussed about the language and write down some key expressions such as adjectives on the whiteboard for later use. Students can also read again the "successful" request email they have read just now as a model.

Step 4: Mutual/Joint construction of the text (10 minutes).

This is an important phase in a genre approach of writing, but the stages also follow a process approach of "pre-planning”, “drafting”, "reflection”, “revision”, “editing and proofreading” and other procedures. (Peer procedures such as peer review will be conducted later in the next step). With the help of computers, teachers write on the screen so that every student can see it via the computer in front of him. Students are also let the teacher pause and make suggestions.

${ }^{1}$ This activity was inspired by software of LINO http://en.linoit.com/. 
Throughout the activity, the teacher keeps asking students if WE (both the instructor and the students) are writing appropriately and remind them of the key expressions on the blackboard. In this way, students are reflecting their own writing.

Meanwhile, the teacher should let the students pay attention to the situation again: "If you were the addressee, what can you feel when you read the email we drafted so far? What do you feel when a student from your course asks for a leave to a conference? How do you expect your students to say to earn your permission? If you were the student asking for the leave, what expressions would you use to express your feelings? Your requests? Your greetings?”

The teacher can also try to let students self-assess the strength of the "successful"/"less successful email on the screen: "Are you convinced by yourself? Can you pose any question to override the request?"If so, then probably a revision is needed.” This step draws much light from a process approach.

Step 5: Individual construction of the text (5 minutes).

Students write individually a request email asking for a leave, explaining to their professor why they need that leave. There should be no peer and teacher interruption. They are writing in their iPad, on the computer, or on a piece of paper.

Step 6: Peer review and revision (10 minutes).

Students stop writing, have a rest, and exchange each other's "emails".

Teachers then give students the following checklists:

Are you convinced of the reason?

Refer to the overall goal. Will the addressee buy it?

What is one of the advantages you find in his email that have been the focus of our discussion today?

Imagine that the addressee will reject the request. Then which part do you suggest needs revision? How to revise? Please write down notes on the margins of the "emails".

If the email is not at all successful, please revise it.

Step 7: Summary, free discussion, Q \& A (5 minutes) \& assignment (5 minutes).

The assignment is to analyze a request email and assess its merits and demerits. Based on the content of the email, rewrite another email.

This assignment tries to motivate students to be critical about others writings as well as their own composition by anchoring themselves to the role of the email writers to understand the relationship between writer intention, reader expectation, and the purpose. The assessment will also help them review what they have learned in the classroom and internalize what have been learned into their existing knowledge system.

\section{Reflection}

In examining whether the five specific objectives have been obtained, the instructor is suggested to reflect as follows:

Objective 1. Students will recognize why there is a need to connect the purpose of the writing to the genre of an email request.

As emphasized, seeking for grant can only be obtained by conforming appropriately to the genre (request email). In this sample lesson, the students were fully aware that the first crucial point of this request email was to pay attention to the genre. The teacher should reflect whether students' attention was geared to genre's influence on the effectiveness of the request email: did they activate schema knowledge, provide stimuli and exploratory materials, and scaffold language input? Here, a genre approach of teaching writing was emphasized.

2. Students will notice the importance of providing and explaining the acceptable reason in a request email (including the exact time for a leave, pointing to a specific place where the conference will be held, etc.).

While analyzing the purpose of the request email and during the process of mutual construction of the text, the teacher mentioned several times the importance of explaining an acceptable reason and expressing it in an appropriate and convincing way. The training also included the comparison between successful and less well-written samples which will help students discover by themselves the appropriateness in provision of the reason. Some reasons were merely vague excuses which are not convincing at all. Students should try to avoid hedging expressions. Through conducting these activities, a genre approach was mainly adopted.

3. Students will recognize the need to raise the awareness that different language use will convey different tones, feelings and functions and thus influencing the achievability of the purpose of the writing. 
Students were asked to compare and conclude from the materials and revise the checklists for writing a request email. This included the language as a recourse for persuasion. Students were guided, for example, in the language scaffolding stage, to specify powerful expressions and syntactic structures. This was intended to help them realize that different language use results in different functions that language played, thus having different results. Therefore, what sentence structure and tense should be employed by the students needed sufficient attention. By reviewing the emphasis of the language choice in relation to the purpose, the take-in of such awareness can be intensified. This was the part where the genre approach came into play.

4. Students will understand the structure of a request email.

Students were taught to realize how to be polite and straightforward in the first sentence of a request email, what was prototypical to state in the next piece of information (the reason), and how to win the addressee's sympathy with the writer by expressing regrets, and how to conclude at the end of the request email. By focusing on the content, the persuasiveness (the purpose) was highlighted, which reflects a genre approach of writing.

5. Students will be able to revise and assess a request email critically.

From the very beginning, the students were required to compare different emails. They were then encouraged to comment on the some checklists for writing a request email; they learned how to peer-review each other's writings; the assignment also helped review how they would evaluate the effectiveness of a real email. All these tasks are aimed at fostering their critical thinking ability and evaluating strategies. Besides, there was also peer revision in the composing of the email. When the instructor frequently asked students if they adhered to the purpose of the email and revised at all times during their writing process, the purpose was to expose them to the recursive nature of viewing writing as a process and from a genre's perspective, integrating social context into their writing.

\section{Limitations}

Information is easily to be overloaded. Students might feel stressful conforming to genre conventions and using appropriate language. It challenges the instructor's management ability to control students' attention and keep them finish each step within the given time. In addition, one-time training of raising students' awareness of process and genre is not sufficient. This method needs concession from students themselves, after they were first exposed to such writing concepts, in order for the successive writing classes to be arranged in similar steps in following lessons. However, the need to raise students' awareness is undoubtedly a transformative view of the L2 writing teaching that needs the students' and teachers' efforts.

\section{References}

Bhatia, V. K. (1999). Integrating Products, Processes and Participants in Professional Writing. In C. N. Candlin, \& K. Hyland (Eds.), Writing: Texts, Processes and Practices (pp. 21-39). London: Longman.

Cheng, A. (2006). Understanding Learners and Learning in ESP Genre-Based Writing Instruction. English for Specific Purposes, 25, 76-89.

Chen, Y. S., \& Su, S. W. (2012). A Genre-Based Approach to Teaching EFL Summary Writing. ELT Journal, 66, $184-192$.

Feez, S. (1998). Text-Based Syllabus Design. Sydney: MacQuarie University/AMES.

Guo, Y. (2005). A Process-Genre Model for Teaching Writing.Conference Paper. English Teaching Forum, 43, 18-26.

Hyland, K. (2003). Genre-Based Pedagogies: A Social Response to Process. Journal of Second Language Writing, 12 , 17-29.

Hyland, K. (2007). Genre Pedagogy: Language, Literacy and L2 Writing Instruction. Journal of Second Language Writing, $16,148-164$.

Kuzborska, I. (2012). Links between Teachers’ Beliefs and Practices and Research on Reading. Reading in a Foreign Language, 23, 102-128.

Swales, J. (1990).Genre Analysis: English in Academic and Research Settings. Cambridge: Cambridge University Press.

Vygotsky, L. S. (1987). Thinking and Speech. In R. W. Rieber, \& A. S. Carton (Eds.), The Collected Works of L. S. Vygotsky (Vol. 1), Problems of General Psychology (pp. 39-285). New York: Plenum Press. (Original Work Published 1934)

Wolfson, N. (1988). The Bulge: A Theory of Speech Behaviour and Social Distance. In J. Fine (Ed.), Second Language Discourse: A Textbook of Current Research (pp. 21-38). Norwood: N.J.: Ablex. 


\section{Appendix I: Five Authentic Emails}

Dear Sir,

I would like to inform you that one of my relative is getting married on 12 March 2009. As I am the eldest in the family, most of the work related to marriage has to be completed by me. For this reason I would like to apply for the four-day leave starting from 10 to 14 March 2009. I assure you that I will complete my pending work once I resume my duty again.

Hope you consider this request and grant me the leave.

Thanks in advance.

Yours,

Charlie

Dear Sir,

I am writing to request you a leave of absence for about two weeks starting from $30^{\text {th }}$ July 2009 for the reason given in this letter. My mother has been diagnosed as having a cyst and needs to undergo surgery for the same. She needs someone to accompany her to the hospital for the surgery and also needs someone to be with her during recovery. The entire process, according to the doctor, will take about two weeks. As my mother and I are the only ones in the family, it is obvious that this responsibility will fall on my shoulders.

Hence I request you to grant me leave for a period of one week starting $30^{\text {th }} \mathrm{July}$.

I shall resume work on 6th August 2009 but if there is any problem, I shall give you prior notice of delay.

Thank you.

With regards,

(The above were adapted from http://www.blurtit.com/q432817.html)

Respected Sir,

This is in lieu of my absence from school for the next few days. I have extreme fever and am fatigued of the cough and cold I have. I have been advised by my family doctor to take complete rest for minimum 5 days. Thus, I wouldn't be able to attend classes from $04^{\text {th }}$ July to $08^{\text {th }}$ July. Please permit me leave for the same.

Thanking you in anticipation.

Regards,

(The above was adapted from http://www.meritnation.com/discuss/question/1732645)

Nisha

Respected Sir,

I would like to inform you that due to some personal reason we are shifting from Baroda .So I would like to apply for the school leaving certificate. So can you help me with that ASAP.

Kindly do the needful.

Thanks.

Yours,

Hi Kai,

Nicho

Due to some personal affairs, I would like to ask for a day's leave for tomorrow (Aug, $15^{\text {th }}$ ). I hope you can understand and approve of my leave.

Best wishes!

Yours,

Ella

(The above were adapted from http://yansc07.blog.sohu.com/97232881.html)

\section{Appendix II: Checklists of a Good Request Email}

Instructions

1. Address the leave of absence letter to the school superintendent.

2. Begin the first sentence of the letter with the length of absence. For example, I am writing to request a leave of absence for seven weeks.

3. Include the starting and ending dates of the leave of absence in the second sentence. For example, my leave would start on September 12, 2011 and end on October 31, 2011. 
4. Explain the reason for the absence in the next paragraph.

5. Clarify in the third paragraph if work, such as grading assignments or developing lesson plans, can be completed before or during the absence.

6. Explain if accrued hours, such as sick or vacation time, are being utilized during the leave.

7. Offer contact information during leave of absence. For example, I will be available through my cell phone at (555) 555-1212. Please contact me, if there are any concerns.

8. Type a closing statement granting the leave along with "Sincerely", and a printed and signed signature.

9. Make three copies of the letter and forward a copy to the superintendent and one to the school principal. (The above was adapted from http://www.ehow.com/how_8416687_write-requesting-leave-absence-teaching.html) 